\title{
Educational Pairings and Fertility Across Europe: How Do the Low-Educated Fare?
}

\author{
Natalie Nitsche, Anna Matysiak, Jan Van Bavel, Daniele Vignoli
}

\begin{abstract}
Recent research suggests that the fertility-education relationship may be mediated by the educational attainment of the partner, especially among the tertiary-educated. However, there are no studies focusing on the couple-educationfertility nexus among couples who achieved only basic educational attainment, even though resource pooling theory predicts differences in family formation by couples' joint levels of socio-economic resources. We address this research gap and investigate how educational pairings among married and cohabiting partners relate to second and third birth transitions across 22 European countries, using data from the EU-SILC (European Union Statistics on Income and Living Conditions) panel and discrete time event history models. Our findings show significantly lower second and third birth transition rates among homogamous low-educated couples compared to heterogamous couples with one low- and one medium or highly-educated partner in the Nordic countries, but not across the rest of Europe. However, couples with one or two low-educated partners have significantly lower second birth rates compared with couples with two highly-educated partners in all European regions.
\end{abstract}

Keywords: Fertility $\cdot$ Education $\cdot$ Couples $\cdot$ Second birth $\cdot$ Europe

\section{Introduction}

Education is one of the most well-studied predictors of childbearing in high-income countries. While causal effects in the relationship between family formation and educational trajectories have proven challenging to assess (Brand/Davis 2011; Stange 2011; Nisén et al. 2013; Impicciatore/Tomatis 2020), it is well known that the obtainment of high levels of education has come hand in hand with the postponement of co-residential union formation, the postponement of parenthood, and increases in childlessness in many nations (Martin 2000; Gustafsson 2001; Shang/Weinberg 2013; Miettinen et al. 2015). Given education expansion and the continuously 
growing group of young adults who complete tertiary education, highly-educated women and men have taken centre stage as subjects of fertility-education research.

However, this literature has focused much less on the childbearing behaviour of the lower-educated. This is unfortunate, as there are reasons to suspect that labour market conditions have evolved in recent decades in ways that are not favourable for the family lives of low-educated adults. Individuals without college degrees have faced significant declines in labour market opportunities, as the number of lowskilled manufacturing jobs has waned (Autor 2014; International Monetary Fund 2018). Moreover, not finishing secondary education is becoming less common across many high-income countries (Eurostat 2021). In consequence, the group of the low-educated (defined as ISCED categories 1 and 2, which usually means 9 years of schooling or less) has become smaller and more selective (OECD 2011). This may be another reason for the observable changes in family formation patterns of this group. Indeed, recent studies suggest that lower-educated individuals are increasingly displaying distinct family formation patterns, underscoring the need to learn more about their childbearing behaviour, and changes therein. For instance, low-educated men are now remaining childless more often than their more highlyeducated counterparts in Finland and Norway (Nisén et al. 2014; Kravdal/Rindfuss 2008), while the incidence of early childbearing appears to have significantly increased among recent cohorts of low-educated women across most of Europe (Raymo et al. 2015). In the Nordic countries, in addition, a differential in completed family size is emerging between the lower- and the highly educated in recent birth cohorts: the lower-educuated tend to either remain childless or have a relatively high number of children, while having exactly two children is most common among those with tertiary education (Jalovaara et al. 2021).

Moreover, an increasing number of studies indicates that the association between education and childbearing life courses can be contingent on the partner's education (Bagavos 2017; Bueno/Garcia-Roman 2021; Cooke 2004; Corijn et al. 1996; Dribe/Stanfors 2010; Nitsche 2014; Nitsche et al. 2018; Trimarchi/Van Bave/ 2020). Like the literature on individuals' fertility, this still scarce but growing literature has focused on the highly-educated, including the only cross-nationally comparative study which examines the association between educational pairings and couples' birth progressions in a wide array of European countries (Nitsche et al. 2018). Very little, however, is known about how the education of the partner may moderate childbearing behaviour among the low-educated. Yet, from an economic perspective, joint educational resources may matter at least as much for birth progressions to them as to couples with higher degrees. Indeed, one recent study of the Finnish context demonstrates significantly lower second birth rates among couples with two low-educated partners compared with heterogamous couples with one low- and one secondary-educated partner (Nitsche et al. 2020). Nonetheless, an overview of how both partners' joint education relates to their childbearing behaviour among the lower-educated over a wider array of countries is lacking.

The aim of this study is to investigate whether the coupling of two low-educated partners may be associated with distinct patterns of childbearing behaviour in a 
wide array of European nations. Using data from the EU-SILC panel study (European Union Statistics on Income and Living Condition) from 22 European countries and discrete time event history models, we examine whether those couples with the lowest joint educational resources display differences in second and third (or higher) order birth transition rates compared with couples in which one of the two or both partners have achieved medium- or high (henceforth "higher") educational attainment. We focus on second and subsequent birth progressions, because educational pairings have been shown to be significantly associated with second and higher-order birth transitions among higher-educated couples across Europe (Nitsche et al. 2018). Moreover, second and higher-order birth transitions often occur relatively close to the previous birth to the same parents, which makes the couple perspective particularly useful. Despite increasing multi-partnered fertility, the large majority of second children in high-income countries are born to couples who continue childbearing after a first birth together (Guzzo 2014; Kreyenfe/d/HeinzMartin 2015). ${ }^{1}$ In our analyses, we further differentiate the subset of heterogamous couples (in which one partner has achieved low and the other some type of higher education) into couples with a low-educated woman and a higher-educated man (hypergamous) and couples with a low-educated man and higher-educated woman (hypogamous). We group countries into four geographical areas (Nordic, Southern, Western, and Central-Eastern Europe) for ease of presentation and based on cultural and societal similarities between the countries in each cluster.

\section{Theoretical background}

Past studies about the couple-education-fertility nexus have derived testable hypotheses from economic theories of the family. One important building block for hypothesis-building has been the concept of opportunity costs, which individuals face when they take time away from the labour market (Happel et al. 1984; Becker 2009). Opportunity costs are particularly relevant for women, because women tend to take the large majority of childbearing- and rearing-related employment breaks and are subjected to larger indirect earnings losses for care work than men (Craig/ Mullan 2011; Carmichael/Charles 2003). When lost work experience is factored in, women with high levels of education and skills face higher opportunity costs (England et al. 2016), which has further directed the research focus to the subgroup of couples with one or two tertiary-educated partners in studies on the role of the (male) partner's resources for childbearing. Nonetheless, economic considerations for childbearing, including incurred opportunity costs for employment breaks and lost income, are likely relevant for the childbearing behaviour of the lower-educated as well.

1 First birth transition rates also varied by educational pairing in previous studies, though mainly in terms of the age at which the first birth occurs in the life course (Nitsche et al. 2018). We also estimated first birth transition rates by educational pairing among our lower-educated sample. These results are not shown, but are available from the authors upon request. 
The new home economics approach, which originates from Becker's work in the early 1980s, suggested that partner role specialisation in labour market versus domestic work is the most efficient system of family organisation (Becker 2009). Accordingly, birth rates would be expected to be highest among couples with specialised roles, such as hypergamous couples with a higher-educated man specializing in the labour market and a lower-educated woman specializing in unpaid domestic and childcare work (Becker 2009). In contrast, resource pooling theory predicts higher birth rates among couples with higher levels of pooled socioeconomic resources. Here, the joint resources may serve as a buffer against the economic insecurity of either partner and enable the family to invest more resources into domestic and childcare services, facilitating simultaneous childrearing and career-building (Oppenheimer 1997). Indeed, evidence from previous studies focusing on the highly-educated subset appears to support resource pooling theory, with several studies demonstrating that couples with two tertiary-educated partners tend to have the highest second and third birth rates across a range of high-income countries in the early $21^{\text {st }}$ century (Dribe/Stanfors 2010; Nitsche et al. 2018; Nitsche et al. 2020; Bueno/Garcia-Roman 2021). Resource pooling, however, also seems relevant for second birth progressions among the lower-educated, at least in the Finnish context (Nitsche et al. 2020).

Thus, joint socio-economic resources and their implications for decision-making around childbearing may be important for couples of all educational and socioeconomic backgrounds, perhaps even more so for the lower-educated. Precarious employment, unemployment, and low pay emerge as important predictors for postponed or forgone childbearing (Modena/Sabatini 2012; Goldstein et al. 2013; Busetta et al. 2019; Vignoli et al. 2020; see Alderotti et al. 2021 for a quantitative review) and have been tied to a lower number of expected children among young adults (Brauner-Otto/Geist 2018). The pooling of resources in the couple may therefore be at least as important for childbearing decision-making among the lower-educated as it is for their higher-educated counterparts. Moreover, motherhood wage penalties, as one element of opportunity costs, have been shown to be about equally large among lower-educated compared with higher-educated women (Budig/Hodges 2010; Killewald/Bearak 2014; England et al. 2016), implying that opportunity cost considerations related to childbearing, and by extension the pooling of resources, may be just as important for childbearing decision-making among lower-educated couples.

\subsection{Hypotheses}

Following Oppenheimer's argument that the pooling of resources has become essential for families' welfare, couples with at least one low-educated partner are socio-economically more vulnerable; likely even more so when both partners have a low level of education (Oppenheimer 1988, 1994, 1997). Therefore, first, couples with two low-educated partners can be expected to display the lowest birth 
transition rates to second and third births, because they have the fewest resources at their disposal.

In contrast, and second, role specialisation arguments imply that high opportunity costs for women's care-related employment breaks could translate into lowest second and third birth rates for hypogamous couples, with a low-educated man and secondary- or tertiary-educated woman. This would apply specifically to couples in which the hypogamous educational pairing translates into a female breadwinner or main-earner arrangement (Van Bavel/Klesment 2017).

A third possible prediction emerges from the bargaining perspective $(\mathrm{Mo} / \mathrm{m} /$ Cook 1995; Bittman et al. 2003). Assuming an equal distribution of fertility desires across educational pairings, hypogamous couples with a higher-educated woman and a low-educated man may display the highest transition rates to second or third births, in the case that she can use her potentially stronger economic standing to negotiate for more support with childrearing with him.

Finally, the partners' educational pairings may be less relevant for couples' second or third birth progressions among lower-educated couples. Two important non-monetary resources needed for childrearing are time and emotional energy (Bianchi et al. 2004; Hochschildt 1979; Goldberg et al. 2002). Low-skilled individuals face barriers in the labour market for career advancement (Holzer 2000) and are more likely to work in occupations which offer fewer career advancement opportunities (Barone et al. 2011; Manzoni et al. 2014). In consequence, low-educated individuals may be faced with fewer "competing devotions," such as simultaneous family formation and career-building, which often requires working over-time and high energy investments (B/air-Loy 2009; Gauthier/de Jong 2021). In consequence, the low-educated may have more time and emotional energy resources at their disposal, outside of regular work hours, to invest in childrearing. If educational pairing effects among tertiary-educated couples operate primarily via income effects which allow for time and energy compensation through the ability to purchase services (childcare, housework help, etc.), educational pairing effects may not be present among couples with one or two low-educated partners.

\subsection{Regional Context}

The relation between educational pairings and progression to second and third births may be moderated by the social context of a given country. Welfare policies offer people some financial security and thus support them in realising their fertility desires even in adverse economic conditions. Consequently, individuals living in countries with greater welfare support would be more likely to have a child despite turbulent economic conditions or a precarious labour market. Besides family policies, labour market policies (such as unemployment benefits, assistance in job searches, and the level of employment protection) may also influence the relationship between educational pairings and fertility by affecting unemployment duration, opportunities for entering employment, and by providing financial support in the case of unemployment (Adserà 2004, 2005). Finally, the incidence of women's labour force participation and the gender division of labour may also affect the 
relationship. In countries where women are less present in the labour market and where the division of labour is more traditional, low-educated women may consider their careers as less important than their male partners' careers. Among European countries, Nordic countries are known for providing strong welfare support and for implementing active labour market policies that facilitate entry into employment (Thévenon 2011). These countries are also characterised by high labour force participation among women and a more egalitarian division of household labour (Altintas/Sullivan 2016). Western Europe also provides strong financial support for the unemployed and has elaborate family policies (Thévenon 2011), but still lags behind the Nordic countries when it comes to women's labour force participation and gender equality in the household (Steiber et al. 2016). Finally, social assistance for families and the unemployed is least generous in Southern Europe and in the post-socialist countries of Central and Eastern Europe (A/derotti et al. 2021). The gender division of labour is heavily asymmetric, both in the east and the south, but women's employment plays a substantially greater role in the former, as it constitutes an important income source for families (Matysiak 2011).

\section{Data, sample and methodological strategy}

\subsection{Data and Sample}

We investigate how low educational attainment of the male partner, the female partner or both is associated with parity transitions using data from the EU-SILC, an ongoing household panel that was launched in 2003 with nearly all EU member states participating by 2005. It provides a household roster and collects detailed information on all household members aged 16 and above. It is a rotational panel by design, meaning that it consists of four subsamples which are interviewed in parallel for four consecutive years (except for Norway and France, where the observation period is 8 years), but each subsample enters the panel at a different point in time. We use EU-SILC data for our study because it provides full household rosters, detailed information on educational attainment and enrolment of all household members, has a longitudinal panel design, covers a wide array of European countries, and is current and ongoing, thereby depicting the current family situation in Europe. The data also has disadvantages, mainly the fairly short observation duration and the lack of retrospective information on fertility and partnership histories, as well as missing educational histories.

We use data from the EU-SILC release 2014 (covering data collected in years 2004-2012) and construct two analytic event history sub-samples, one for the transition to second births, and the other to third or higher order births. The EUSILC does not provide information on non-resident children or previous dates of union formation and dissolutions. Therefore, fertility histories were reconstructed from the information on household composition, relationship statuses within the households, and the birth years of their members. We limit our analysis to cohabiting and married couples involving women aged 18-35 for all three samples. 
The construction of fertility histories through the household roster implies the possibility of left-truncation. In other words, if children were born when their mothers were very young, they may already have left the parental home before their mother turned 35, which is especially likely among lower-educated individuals who tend to make the transition to parenthood earlier in the life course than individuals who obtain more education. Our data does not allow us to take union duration or time since completing education into account, hence we cannot control for this selectivity in the analyses.

We focus on continued childbearing, because educational pairing differences in first births appear to relate primarily to birth timing (Nitsche et al. 2018), which may yield less couple-level variation among the lower-educated, who, on average, have their children early in the adult life course (Rindfuss/John 1983). Also, birth rate differences between educational pairings appear to be most pronounced with respect to second births. The sample of couples exposed to second, third, or higher order birth risks consists of unions including a woman who meets the age conditions listed above and who were living with at least one child aged 5 or younger. The condition on the age of the child was introduced in order to exclude couples from the sample who were rather unlikely to give birth to another child, either because of their preferences, health conditions, or union quality. Moreover, including longer birth intervals would make it more likely that the current partner is a new partner and not the biological parent of the older sibling(s) (Kreyenfeld/Heinz-Martin 2015). This restriction excludes one-fifth of second births and a little less than one-third of third births, as 80 percent of second births and 70 percent of thirds births observed in our pooled sample occurred within 5 years after the birth of the previous child. All couples were considered at risk for childbearing until that event occurred, until union disruption, or until the date of the exit from the panel, whichever came first. Both partners were allowed to re-enter the sample in case they formed another union during the panel.

The EU-SILC offers panel data for 30 European countries, 22 of which are included in our sample. We excluded data from Spain and Ireland due to nonresponse substitution conducted in these countries for households that dropped out, causing subsequent issues with representativeness (Iacovou et al. 2012). In addition, we found unrealistically low numbers of births by exposure time in Cyprus, Malta, and Romania when compared to the period TFR. We therefore excluded these countries from the sample as well. Finally, we excluded Bulgaria and Lithuania, as these countries have particularly high attrition rates, which has been shown to bias fertility estimates based on the EU-SILC (Greulich/Dasré 2017).

We clustered the single-country samples into four sub-samples of country groups. Our Nordic country group includes Denmark, Finland, Norway, and Sweden; the Western group comprises Austria, Belgium, France, Luxembourg, the Netherlands, and the UK; the Southern group consists of Greece, Italy, and Portugal; and the Central-Eastern European group includes the Czech Republic, Estonia, Croatia, Hungary, Latvia, Poland, Slovenia, and Slovakia. 


\subsection{Models and Covariates}

\subsubsection{Dependent Process and Models}

As our data are measured annually, we estimated discrete time event history models separately for the transitions to second and to third and higher-order births. Couplelevel random effects were added to the models in order to account for the correlation across observation years on the couple level. We constructed indicator variables which measure the actual combinations of her and his educational attainment. In order to avoid the number of pairings becoming intractably large, we measured his and her education in three main groups: low, medium, and high. Low education corresponds to the International Standard Classification of Education (ISCED) 0, 1, and 2 (i.e. lower secondary or second stage of basic education at most), medium education to ISCED 3 and 4 (i.e. upper secondary and post-secondary non-tertiary) and high education to ISCED 5 and 6 (first and second stage of tertiary education). The three pairing categories which are of main interest for our analyses are those that include the low education levels, i.e. when both partners have low education (homogamous), when the woman has low education while the man has higher education (medium or high education, hypergamous), and when the man has low education while the woman has higher education (medium or high education, hypogamous). Of the remaining categories, we only show results for couples with a) two partners with a medium level of education, as this is the most common pairing in many countries, and b) two highly educated partners, as this is the pairing with the highest second and subsequent birth transition rates across Europe.

\subsubsection{Covariates}

The relationship between educational pairing and second and third (and higher parity) birth risks is estimated net of her and his enrolment in education, her age, the absolute difference between his and her age in years, marital status (married vs. cohabitation), year dummies to control for period effects, and country dummies to control for differences in birth rates between the single countries within the groupings. In the EU-SILC, enrolment is defined as being currently enrolled in the formal education system, meaning either primary, secondary, or tertiary schooling. Vocational training activities outside of the formal education system do not qualify as enrolment in this definition. Educational attainment is measured as the highest ISCED level attained at the time of interview. We treat both educational enrolment and attainment as time-varying covariates and allow for entry in and exit from enrolment as well as educational upgrading of either partner. Enrolment and attainment level are lagged by one year, as we are interested in the relative educational pairing at the time of conception. We furthermore control for the woman's age at first birth in order to account for time squeeze effects experienced by women who made the transition to the first child at later ages, the age of the youngest child, and a squared term for the age of the youngest child. 
Some limitations of our empirical approach should be mentioned at the outset. Most importantly, our data provide only a snapshot of couples' life courses and do not allow us to distinguish between timing and quantum effects. Thus, we are unable to verify whether couples who did not have a (next) child within three years eventually had one later on. Second, we are unable to control for a selection of certain couples into stable unions or parenthood. Our findings about the determinants of couples' second and third birth rates therefore do not allow conclusions about completed fertility. It is possible that couples of some educational pairings are less likely to separate than others, and hence have longer exposures to the "risk" of childbearing, so that elevated birth rates may be partly driven by higher union stability.

\subsection{Sample Descriptive Statistics}

Tables 1a and $1 \mathrm{~b}$ provide an overview of the number of couple-years and events by educational pairing and country cluster in our analytic sample. There is marked variation in the distribution of educational pairings across regional clusters. Low educational attainment is widespread across Southern Europe, but not in the other clusters. In the Southern European cluster, about half of the couples (meaning couple-years) at risk of second or third (or higher order) birth feature at least one partner with low education. This applies to only roughly 20 percent of coupleyears at risk in Western Europe, and to around 15 percent of couple-years at risk in Northern and Central-Eastern Europe (for time at risk of second births, distributions for third birth risks differ slightly). Consequently, the number of birth events in our sample is small among couples with one low-educated partner in some of the clusters, particularly in the low-low educated pairing in the Nordic countries for both second and third birth transitions. But this also applies to the number of third and higher-order birth events in the Southern European cluster among heterogamous couples with one low- and one higher-educated partner. Parity progressions to third and higher-order births are less frequent in Southern European countries generally speaking, compared to other European countries (Frejka 2008), which likely is a factor behind the lower number of third birth events in this cluster. Results for the Nordic countries and for third birth transitions in the Southern European cluster thus need to be interpreted with caution. 
542 - Natalie Nitsche, Anna Matysiak, Jan Van Bavel, Daniele Vignoli

Tab. 1a: Analytic sample second births

\begin{tabular}{|c|c|c|c|c|}
\hline Educational Pairing & Nordic & Western & Southern & Eastern \\
\hline \multicolumn{5}{|l|}{ Both high } \\
\hline exposure \% & 29.58 & 26.04 & 9.41 & 16.7 \\
\hline exposure years & 905 & 1212 & 330 & 1270 \\
\hline events N & 223 & 355 & 55 & 164 \\
\hline \multicolumn{5}{|l|}{ She high he medium } \\
\hline exposure \% & 20.49 & 15.86 & 8.13 & 17.18 \\
\hline exposure years & 627 & 738 & 285 & 1307 \\
\hline events $\mathrm{N}$ & 157 & 167 & 47 & 123 \\
\hline \multicolumn{5}{|l|}{ She medium he high } \\
\hline exposure \% & 7.81 & 9.05 & 4.51 & 5.96 \\
\hline exposure years & 239 & 421 & 158 & 453 \\
\hline events $\mathrm{N}$ & 47 & 98 & 25 & 42 \\
\hline \multicolumn{5}{|l|}{ Both medium } \\
\hline exposure \% & 27.65 & 29.03 & 30.54 & 46.01 \\
\hline exposure years & 846 & 1351 & 1071 & 3500 \\
\hline events $\mathrm{N}$ & 203 & 284 & 139 & 335 \\
\hline \multicolumn{5}{|l|}{ She low he higher } \\
\hline exposure \% & 5.23 & 6.08 & 8.61 & 4.05 \\
\hline exposure years & 160 & 283 & 302 & 308 \\
\hline events $\mathrm{N}$ & 38 & 57 & 31 & 42 \\
\hline \multicolumn{5}{|l|}{ He low she higher } \\
\hline exposure \% & 5.72 & 7.58 & 16.74 & 5.67 \\
\hline exposure years & 175 & 353 & 587 & 431 \\
\hline events $\mathrm{N}$ & 28 & 64 & 62 & 42 \\
\hline \multicolumn{5}{|l|}{ Both low } \\
\hline exposure \% & 3.53 & 6.36 & 22.07 & 4.44 \\
\hline exposure years & 108 & 296 & 774 & 338 \\
\hline events $\mathrm{N}$ & 11 & 57 & 96 & 23 \\
\hline
\end{tabular}

Source: EU-SILC 2014 release, covering data collected from 2004 to 2012, own estimations 
Tab. 1b: Analytic sample third and higher-order births

\begin{tabular}{|c|c|c|c|c|}
\hline Educational Pairing & Nordic & Western & Southern & Eastern \\
\hline \multicolumn{5}{|l|}{ Both high } \\
\hline exposure $t \%$ & 25.2 & 21.38 & 6.19 & 12.94 \\
\hline exposure years & 1473 & 1720 & 230 & 1360 \\
\hline events $\mathrm{N}$ & 79 & 129 & 9 & 47 \\
\hline \multicolumn{5}{|l|}{ She high he medium } \\
\hline exposure t \% & 19.07 & 12.17 & 5.76 & 11.25 \\
\hline exposure years & 1115 & 979 & 214 & 1182 \\
\hline events $\mathrm{N}$ & 46 & 46 & 6 & 19 \\
\hline \multicolumn{5}{|l|}{ She medium he high } \\
\hline exposure $t \%$ & 8.52 & 8.7 & 4.55 & 5.53 \\
\hline exposure years & 498 & 700 & 169 & 581 \\
\hline events $\mathrm{N}$ & 28 & 40 & 4 & 15 \\
\hline \multicolumn{5}{|l|}{ Both medium } \\
\hline exposure $t \%$ & 29.8 & 31.43 & 25.75 & 49.38 \\
\hline exposure years & 1742 & 2528 & 957 & 5189 \\
\hline events $\mathrm{N}$ & 85 & 115 & 25 & 87 \\
\hline \multicolumn{5}{|l|}{ She low he higher } \\
\hline exposure t \% & 7.2 & 8.66 & 10.52 & 6.95 \\
\hline exposure years & 421 & 697 & 391 & 730 \\
\hline events $\mathrm{N}$ & 21 & 38 & 12 & 38 \\
\hline \multicolumn{5}{|l|}{ He low she higher } \\
\hline exposure t \% & 6.69 & 7.52 & 16.01 & 6.46 \\
\hline exposure years & 391 & 605 & 595 & 679 \\
\hline events $\mathrm{N}$ & 30 & 40 & 18 & 24 \\
\hline \multicolumn{5}{|l|}{ Both low } \\
\hline exposure t \% & 3.52 & 10.13 & 31.23 & 7.49 \\
\hline exposure years & 206 & 815 & 1161 & 787 \\
\hline events $\mathrm{N}$ & 5 & 55 & 43 & 31 \\
\hline
\end{tabular}

Source: EU-SILC 2014 release, covering data collected from 2004 to 2012, own estimations

\section{$4 \quad$ Results}

We illustrate our results by providing a series of figures that plot predicted birth probabilities by years elapsed since the birth of the previous child separately by country group and parity. Figures 1 and 2 show the predicted second and third birth probabilities from our models for each educational pairing and for each year since the birth of the previous child, by parity and country cluster. Using the nlcom command in Stata 14, we estimated standard errors and 95 percent confidence intervals around the predicted values, holding the values of the other covariates constant at 
their mean or modal values. The figures display the predicted birth probabilities and indicate graphically whether the predicted values of the shown educational pairing groups differ significantly from the reference category: couples in which both partners have a low level of education. We chose not to display confidence interval bands for easier readability; instead, the line type indicates whether the birth probability of the displayed educational pairing differs significantly from that of the reference group. The threshold for statistical significance was set at the 10 percent level $(p$-value <.10). The reference category we chose here are couples with two low-educated partners (the line for whom is always red and solid). Solid lines for the other educational pairings indicate significant differences to this reference category, while dotted lines mean that the difference in the predicted probabilities of this specific educational pairing and the reference group is statistically insignificant.

Figure 1 (panels a-d) shows the predicted second birth probabilities by years elapsed since the first birth. In Western, Central-Eastern, and Southern Europe, there are no significant differences in parity progressions to second births between couples with two low-educated partners and couples with one low-educated partner and one with more education. However, such differences do appear to exist in the Nordic countries. Here, homogamous low-educated couples display significantly lower predicted parity progressions to second births than couples with one loweducated partner only. However, couple-years at risk and the number of events for the low-educated groupings in the Nordic countries are low, as the group of loweducated individuals is a rather small minority across North European countries, so case numbers may be too low for this result to be representative. A second result that stands out across the country groupings is that couples with either one or two low-educated partners display lower parity progressions to second births than couples with two highly-educated partners throughout.

Parity progressions to third births look similar to second birth transitions (Figure 2 (panels a-d)). There are no significant differences between the educational pairings involving one or two low-educated partners in Southern Europe. The Nordic countries again display significantly different third birth rates between the low-educated pairings. Both types of couples involving only one low- and one higher-educated partner have accelerated progressions to third births, compared to homogamous low-educated couples, but these predictions are based on small case numbers. In the Central and Central-Eastern European cluster, hypogamous unions with a low-educated man and a higher-educated woman have significantly lower third birth rates than homogamous low educated couples do, but only in years 2-5 after the second birth. 
Fig. 1: $\quad$ Predicted second birth probabilites by educational pairing and country cluster

(a) Nordic - Second Births

Predicted probability of giving birth

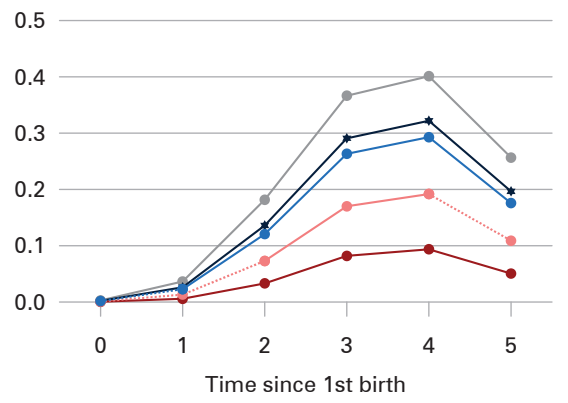

(c) Southern - Second Births

Predicted probability of giving birth

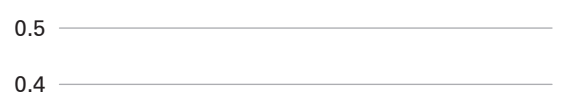

0.4

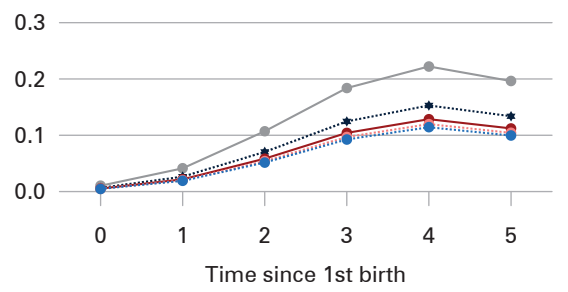

(b) Western - Second Births

Predicted probability of giving birth

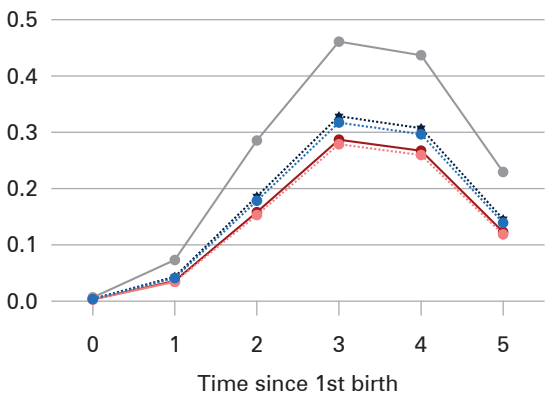

(d) Central- and Eastern - Second Births

Predicted probability of giving birth

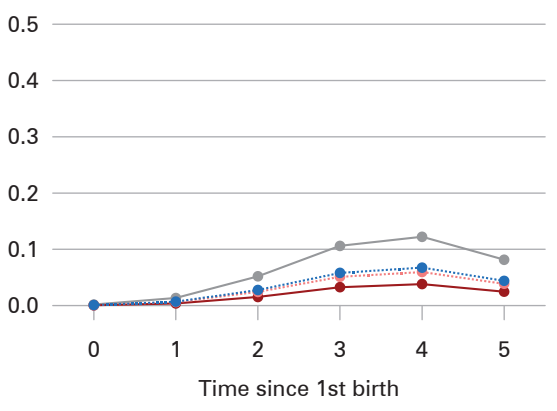

$\longrightarrow$ both high $\longrightarrow$ both medium $\longrightarrow$ both low $\longrightarrow$ he low she higher $\longrightarrow$ she low he higher

Legend: "both high": both are highly educated (homogamous); "both medium": both are medium educated (homogamous); "both low": both are low educated (homogamous); "he low she higher": he has low education while she has higher education (medium or high education, hypogamous); "she low he higher": she has low education while he has higher education (medium or high education, hypergamous).

Note: homogamous low educated couples serve as the reference category, they are always depicted as a solid red line. The remaining lines are solid if the difference in the birth probability between the represented pairing and the reference group is significant at $p<0.1$; they are dotted if the difference is not significant.

Source: EU-SILC 2014 release, covering data collected from 2004 to 2012, own estimations 
Fig. 2: Predicted third and higher order birth probabilities by educational pairing and country cluster

(a) Nordic - Third (+) Births Predicted probability of giving birth

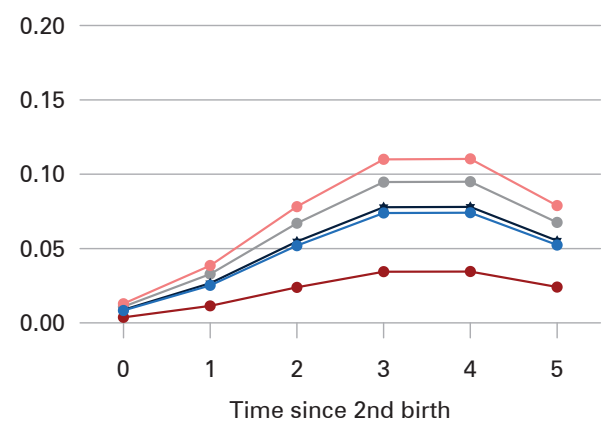

(c) Southern - Third (+) Births Predicted probability of giving birth 0.20 0.15
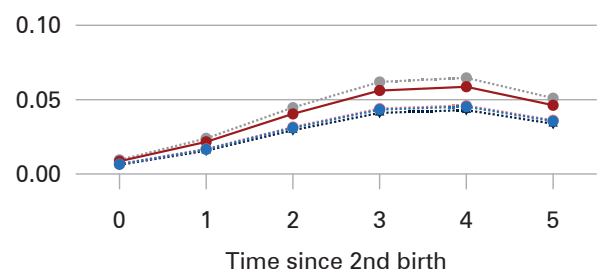

(b) Western - Third (+) Births Predicted probability of giving birth

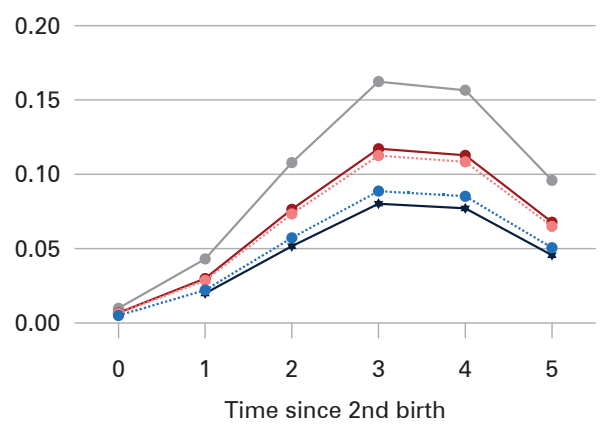

(d) Central- and Eastern - Third (+) Births Predicted probability of giving birth 0.20

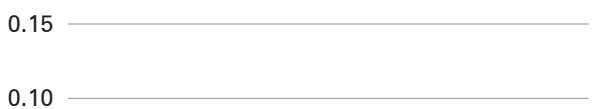

0.05

0.00

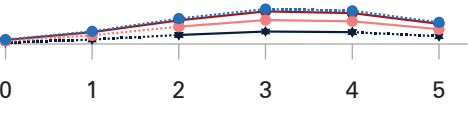

Time since 2nd birth

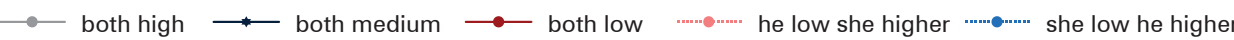

Legend: "both high": both are highly educated (homogamous); "both medium": both are medium educated (homogamous); "both low": both are low educated (homogamous); "he low she higher": he has low education while she has higher education (medium or high education, hypogamous); "she low he higher": she has low education while he has higher education (medium or high education, hypergamous).

Note: homogamous low educated couples serve as the reference category, they are always depicted as a solid red line. The remaining lines are solid if the difference in the birth probability between the represented pairing and the reference group is significant at $\mathrm{p}<0.1$; they are dotted if the difference is not significant.

Source: EU-SILC 2014 release, covering data collected from 2004 to 2012, own estimations 


\section{$5 \quad$ Discussion and conclusions}

Previous research indicates that second and third birth rates vary systematically by couples' educational pairings across a wide array of European regions, i.e. that the association between an individual's level of education and their fertility trajectory can be contingent on the partner's level of education. This literature has focused on couples with high levels of education (e.g. Nitsche et al. 2018), leaving the question of whether birth rates among lower-educated individuals vary systematically by the education of the partner unaddressed. Our study addressed this gap. We examined progression rates to second and third births by educational pairings among heterosexual couples with one or two low-educated partners, using data from the EU-SILC on 22 countries, which we clustered into the four broader regions of the Nordic countries and Western, Southern, and Central-Eastern Europe.

Four main findings emerged.

First, apart from the Nordic countries, there are no differences in second birth probabilities between couples with one and two low-educated partners across Europe. The same pattern applies to third and higher parity births, the only exception being that hypogamous couples with a low-educated man and a highereducated woman have significantly lower third birth probabilities in Central-Eastern Europe than homogamous low-low educated couples. Overall, these results do not support the resource pooling hypotheses, the gender role hypothesis, and the bargaining hypothesis for lower educated couples' fertility behaviour in Western and Southern Europe, and in Central-Eastern Europe concerning second births. While we cannot measure any of the underlying mechanisms, our findings hint at different dynamics, or more varied, less systematic dynamics with respect to couples' educational pairings and second or third and higher-order births among lower-educated couples, compared to more highly-educated couples. In particular, resource pooling does not appear to play the same systematic role for lowereducated couples' continued childbearing than studies suggest it does among more highly-educated couples (Dribe/Stanfors 2010; Nitsche et al. 2018). However, our analyses do not contain information on income. It is possible that, on average, gains in earned income for an educational increase from low to medium education are less steep than gains from medium to tertiary education. This means that pooling effects might still emerge for couples whose heterogamous coupling of one low and one higher educated partner implies higher income gains. The same may apply to other resources which potentially accompany tertiary education, such as social networks, housing conditions, health, and access to a wider array of health services. In other words, resource pooling among couples with one lowand one medium-educated partner may not have the same meaning, or may come with a larger variation in pooling gains compared to resource pooling among two tertiary-educated individuals. Alternatively, couples with one or two low-educated individuals may not be in the same need of additional purchased services, which become affordable via resource pooing, in order to realise a second or third birth. If low-educated individuals have a greater availability of time and energy resources to invest into their children - for instance because their job demands bleed less into 
their private lives - investments into private services may be needed less often to realise second and third childbearing. Our study is limited in that it cannot address these potential mechanisms underlying the detected patterns. Future research is needed to investigate these potential pathways with adequate data.

Second, the Nordic countries stand out. Here, we do find some evidence for the resource pooling hypothesis among the lower-educated subset of couples. Couples with the lowest joint human capital (i.e. low education for both) exhibit delayed or forgone progressions to second and third births in this country group, compared with couples in which one partner has low and the other has secondary or tertiary education. These findings for the Nordic country group support Oppenheimer's pooling argument: couples with the lowest joint human capital may be those facing the most constraints in making the decision for another child in the Nordic countries. This is noteworthy, because the Nordic countries generally provide high levels of welfare state transfers to families (Gupta et al. 2008). However, we need to interpret these results with great caution, as they hinge upon the small number of couples with homogamous low education and a very small number of events in our data. Nonetheless, they corroborate findings from a recent study, drawn from large samples from Finnish registers, which shows significantly lower second birth transition rates for low-low-educated couples, compared with all other educational pairing types (Nitsche et al. 2020). Future research is needed to confirm these patterns and investigate underlying reasons for these lowest second and higher order birth transition rates among homogamous low-educated couples in the Nordic countries. Future work should also take differences in union dissolution probabilities by educational pairing into account, which our study did not, representing a further limitation to interpreting our findings. Previous studies demonstrate differences in divorce and union dissolution risks by educational pairing. Low-low-educated couples have the highest divorce risks (Lyngstad 2004) in Norway, and the highest risk to separate when cohabiting (Mäenpää/Jalovaara 2014) in Finland. Eventhistory estimates are sensitive to differences in exposure time, in other words, the significantly lower birth rates among the low-low-educated pairings in the Nordic countries may hinge on their particularly high union dissolution risks, because they are no longer at risk of having another child when they leave the estimation sample due to a union dissolution.

Third, hypogamous couples with a low-educated woman and a higher-educated man had slightly lower third birth probabilities than the homogamous low-loweducated couples in Central and Eastern Europe. We cannot test whether this educational pairing translates into female breadwinner arrangements. However, female breadwinner arrangements are both more culturally accepted and significantly more common across Central-Eastern European countries (Haas et al. 2006). It is possible that female breadwinner couples among the lower-educated groups can afford a third child less often or not as soon as low-low-educated couples, because they rely on the woman's income more heavily to sustain the family.

The fourth and final finding from our analyses is that couples with one or two low-educated partners have significantly lower progressions to second births in all country clusters, and to third births in Northern and Western Europe, compared to 
couples with two highly-educated partners. More research is needed to address whether these differences in birth rates between high-high and the other educational pairings are driven by differences in union stability across educational pairings; the availability of economic resources such as employment, employment security, and financial well-being; or other resources which are acquired through or correlated with education, such as social capital and networks, health, access to health care services, and psychological-emotional resources, such as differences in stress management and conflict resolution skills. Further work is needed for the closer examination of these questions, and to disentangle quantum and timing effects, although this is difficult to assess methodologically and requires more detailed data featuring full fertility and partnership histories.

\section{Acknowledgements}

The research leading to these results was supported with funding from the European Union's Seventh Framework Programme (FP7/2007-2013) under the following grant agreements: 1) no. 627543 for COUPFER/Marie Curie Action (Natalie Nitsche), 2) ERC Grant Agreement no. 312290 for the GENDERBALL project (Jan Van Bavel), and 3) ERC Grant Agreement no. 725961 for the EU-FER project (Daniele Vignoli). Further support for this research was provided to Natalie Nitsche by the Austrian Science Foundation (FWF) within the Lise Meitner Programme under Grant Agreement M 2188-G16 and to Anna Matysiak by the Polish National Agency of Academic Exchange (NAWA) under the Polish Returns 2019 Programme.

We are grateful to Tymon Słoczyński for his help at the early stages of this project.

\section{References}

Adserà, Alícia 2004: Changing fertility rates in developed countries. The impact of labor market institutions. In: Journal of Population Economics 17,1: 17-43. https://doi.org/10.1007/s00148-003-0166-x

Adserà, Alícia 2005: Vanishing children: From high unemployment to low fertility in developed countries. In: American Economic Review 95,2: 189-193. https://doi.org/10.1257/000282805774669763

A/derotti, Giammarco et al. 2021: Employment Instability and Fertility: A Meta-Analysis. In: Demography 58,3: 871-900. https://doi.org/10.1215/00703370-9164737

Altintas, Evrim; Sullivan, Oriel 2016: Fifty years of change updated: Cross-national gender convergence in housework. In: Demographic Research 35,16: 455-470. https://doi.org/10.4054/DemRes.2016.35.16

Autor, David H. 2014: Skills, education, and the rise of earnings inequality among the "other 99 percent." In: Science 344,6186: 843-851. http://dx.doi.org/10.1126/science.1251868

Bagavos, Christos 2017: Do different educational pairings lead to different fertility outcomes? A cohort perspective for the Greek case. In: Vienna Yearbook of Population Research 15: 215-237. https://doi.org/10.1553/populationyearbook2017s215 
Barone, Carlo; Lucchini, Mario; Schizzerotto, Antonio 2011: Career mobility in Italy: A growth curves analysis of occupational attainment in the twentieth century. In: European Societies 13,3: 377-400. https://doi.org/10.1080/14616696.2011.568254

Becker, Gary S., 2009: A Treatise on the Family. Harvard university press.

Bianchi, Suzanne M. et al. 2004: Inequality in parental investment in child-rearing: Expenditures, time, and health. In: Social inequality 189-219.

Blair-Loy, Mary 2009: Competing devotions: Career and family among women executives. Harvard University Press.

Bittman, Michael et al. 2003: When does gender trump money? Bargaining and time in household work. In: American Journal of sociology 109,1: 186-214. https://doi.org/10.1086/378341

Brand, Jennie E.; Davis, Dwight 2011: The impact of college education on fertility: Evidence for heterogeneous effects. In: Demography 48,3: 863-887. https://doi.org/10.1007/s13524-011-0034-3

Brauner-Otto, Sarah R.; Geist, Claudia 2018: Uncertainty, doubts, and delays: Economic circumstances and childbearing expectations among emerging adults. In: Journal of Family and Economic Issues 39,1: 88-102. https://doi.org/10.1007/s10834-017-9548-1

Bueno, Xiana; García-Román, Joan 2021: Rethinking Couples' Fertility in Spain: Do Partners' Relative Education, Employment, and Job Stability Matter? In: European Sociological Review 4: 571-587. https://doi.org/10.1093/esr/jcaa070

Budig, Michelle J.; Hodges, Melissa J. 2010: Differences in disadvantage: Variation in the motherhood penalty across white women's earnings distribution. In: American Sociological Review 75,5. 705-728. https://doi.org/10.1177/0003122410381593

Busetta, Annalisa; Mendola, Daria; Vignoli, Daniele 2019: Persistent joblessness and fertility intentions. In: Demographic Research 40: 185-218. https://dx.doi.org/10.4054/DemRes.2019.40.8

Carmichael, Fiona; Charles, Susan 2003: The opportunity costs of informal care: does gender matter? In: Journal of health economics 22,5: 781-803. https://doi.org/10.1016/S0167-6296(03)00044-4

Cooke, Lynn Prince 2004: The gendered division of labor and family outcomes in Germany. In: Journal of Marriage and Family 66,5: 1246-1259. https://doi.org/10.1111/j.0022-2445.2004.00090.x

Corijn, Martine; Liefbroer, Aart C.; de Jong Gierveld, Jenny 1996: It takes two to tango, doesn't it? The influence of couple characteristics on the timing of the first child. In: Journal of Marriage and the Family 58,1: 117-126. https://doi.org/10.2307/353381

Craig, Lyn; Mullan, Killian 2011: How mothers and fathers share childcare: A crossnational time-use comparison. In: American sociological review 76,6: 834-861.

Dribe, Martin; Stanfors, Maria 2010: Family life in power couples. Continued childbearing and union stability among the educational elite in Sweden, 1991-2005. In: Demographic Research 23,30: 847-877. https://dx.doi.org/10.4054/DemRes.2010.23.30

England, Paula et al. 2016: Do highly paid, highly skilled women experience the largest motherhood penalty? In: American Sociological Review 81,6: 1161-1189. https://doi.org/10.1177/0003122416673598

Eurostat 2021: Data on population by educational attainment level, sex, and age (\%) - main indicators [https://appsso.eurostat.ec.europa.eu/nui/show.do?dataset=edat Ifse_04\&lang=en, 06.10.2021]. 
Frejka, Tomas 2008: Overview Chapter 2: Parity distribution and completed family size in Europe: Incipient decline of the two-child family model? In: Demographic research 19: 47-72. https://dx.doi.org/10.4054/DemRes.2008.19.4

Gauthier, Anne H.; de Jong, Petra W. 2021: Costly children: the motivations for parental investment in children in a low fertility context. In: Genus 77, 6. https://doi.org/10.1186/s41118-020-00111-5

Goldberg, Wendy A. et al. 2002: Emotional energy as an explanatory construct for fathers' engagement with their infants. In: Parenting: Science and Practice 2,4: 379. 408. http://dx.doi.org/10.1207/S15327922PAR0204_03

Goldstein, Joshua R. et al. 2013: Fertility reactions to the "Great Recession" in Europe: Recent evidence from order-specific data. In: Demographic research 29: 85-104. https://doi.org/10.4054/DemRes.2013.29.4

Greulich, Angela; Dasré, Aurélien 2017: The quality of periodic fertility measures in EUSILC. In: Demographic Research 36: 525-556. https://dx.doi.org/10.4054/DemRes.2017.36.17

Gupta, Nabanita Datta; Smith, Nina; Verner, Mette 2008: The impact of Nordic countries' family friendly policies on employment, wages, and children. In: Review of Economics of the Household 6,1: 65-89. https://doi.org/10.1007/s11150-007-9023-0

Gustafsson, Siv 2001: Optimal age at motherhood. Theoretical and empirical considerations on postponement of maternity in Europe. In: Journal of Population Economics 14,2: 225-247. https://doi.org/10.1007/s001480000051

Guzzo, Karen Benjamin 2014: New partners, more kids: Multiple-partner fertility in the United States. In: The Annals of the American Academy of Political and Social Science 654,1: 66-86. https://dx.doi.org/10.1177/0002716214525571

Hochschild, Arlie Russell 1979: Emotion work, feeling rules, and social structure. In: American journal of sociology 85,3: 551-575. https://doi.org/10.1086/227049

Haas, Barbara et al. 2006: Household employment patterns in an enlarged European Union. In: Work, employment and society 20,4: 751-771. https://doi.org/10.1177/0950017006069813

Happel, Stephen K.; Hill, John K.; Low, Stuart A. 1984: An economic analysis of the timing of childbirth. In: Population studies 38,2: 299-311. https://doi.org/10.2307/2174078

Holzer, Harry 2000: Career advancement prospects and strategies for low-wage minority workers. Washington, DC: The Urban Institute [https://www.urban.org/sites/default/ files/publication/63886/410403-career-advancement-prospects-and-strategies-forlow-wage-minority-workers.pdf, 20.10.2021].

lacovou, Maria; Kaminska, Olena; Levy, Horacio 2012: Using EU-SILC data for crossnational analysis: Strengths, problems and recommendations. ISER Working Paper Series No. 2012-03. Essex, UK: University of Essex, Institute for Social and Economic Research.

Impicciatore, Roberto; Tomatis, Francesca 2020: The nexus between education and fertility in six European countries. In: Genus 76, 35. https://doi.org/10.1186/s41118-020-00104-4

International Monetary Fund 2018: World Economic Outlook: Cyclical Upswing, Structural Change. Washington, DC.

Jalovaara, Marika; Andersson, Linus; Miettinen, Anneli 2021: Parity disparity: Educational differences in Nordic fertility across parities and number of reproductive partners. In: Population Studies 1-18. https://doi.org/10.1080/00324728.2021.1887506 
Killewald, Alexandra; Bearak, Jonathan 2014: Is the motherhood penalty larger for lowwage women? A comment on quantile regression. In: American Sociological Review 79,2: 350-357. https://doi.org/10.1177/0003122414524574

Kravdal, Øystein; Rindfuss, Ronald R. 2008: Changing relationships between education and fertility: A study of women and men born 1940 to 1964. In: American Sociological Review 73,5: 854-873. https://doi.org/10.1177/000312240807300508

Kreyenfeld, Michaela; Andersson, Gunnar; Pailhé, Ariane 2012: Economic uncertainty and family dynamics in Europe: Introduction. In: Demographic Research 27,28: 835852. https://dx.doi.org/10.4054/DemRes.2012.27.28

Kreyenfeld, Michaela; Heintz-Martin, Valerie 2015: Fertility after separation: Second births in higher order unions in Germany. FamiliesAndSocieties Working Paper Series 28. Brussels, Belgium: European Commission, Research and Innovation [http://www.familiesandsocieties.eu/GGTSPU-5ed16d5fbc77ce2171907-773430-novznD46gDWEPRJm-LOD/wp-content/uploads/2015/02/ WP28KreyenfeldHeintzMartin2015.pdf, 09.11.2021].

Lyngstad, Torkild 2004: The impact of parents' and spouses' education on divorce rates in Norway. In: Demographic research 10: 121-142. https://dx.doi.org/10.4054/DemRes.2004.10.5

Mäenpää, Elina; Jalovaara, Marika 2014: Homogamy in socio-economic background and education, and the dissolution of cohabiting unions. In: Demographic research 30: 1769-1792. https://dx.doi.org/10.4054/DemRes.2014.30.65

Manzoni, Anna; Härkönen, Juho; Mayer, Karl Ulrich 2014: Moving on? A growth-curve analysis of occupational attainment and career progression patterns in West Germany. In: Social Forces 92,4: 1285-1312. https://doi.org/10.1093/sf/sou002

Martin, Steven P. 2000: Diverging Fertility among U.S. Women who Delay Childbearing Past Age 30. In: Demography 37,4: 523-533. https://doi.org/10.2307/2648078

Matysiak, Anna 2011: Interdependencies between fertility and women's labour supply. Springer Science \& Business Media. https://doi.org/10.1007/978-94-007-1284-3

Miettinen, Anneli et al. 2015: Increasing childlessness in Europe: time trends and country differences. FamiliesAndSocieties Working Papers Series 33 [http:// www.familiesandsocieties.eu/GGTSPU-5ed16d5fbc77ce21-40919-1849773T0w8hgaQnYs3Wq3F-LOD/wp-content/uploads/2015/03/WP33MiettinenEtAI2015. pdf, 09.11.2021]

Modena, Francesca; Sabatini, Fabio 2012: I would if I could: Precarious employment and childbearing intentions in Italy. In: Review of Economics of the Household 10,1: 77-97. https://doi.org/10.1007/s11150-010-9117-y

Molm, Linda D.; Cook, Karen S. 1995: Social exchange and exchange networks. In: Sociological perspectives on social psychology 2,3: 209-235.

Nisén, Jessica et al. 2013: Educational differences in completed fertility: a behavioral genetic study of Finnish male and female twins. In: Demography 50,4: 1399-1420. https://doi.org/10.1007/s13524-012-0186-9

Nisén, Jessica et al. 2014: Age-specific fertility by educational level in the Finnish male cohort born 1940-1950. In: Demographic research 31: 119-136. https://doi.org/10.4054/DemRes.2014.31.5

Nitsche, Natalie 2014: Fertility, Education, and Couple Dynamics: Three Essays on Childbearing Behavior in the United States and Germany. Yale University (Doctoral dissertation). 
Nitsche, Natalie et al. 2018: Partners' educational pairings and fertility across Europe. In: Demography 55,4: 1195-1232. https://doi.org/10.1007/s13524-018-0681-8

Nitsche, Natalie; Trimarchi, Alessandra; Jalovaara, Marika 2020: Couples' educational pairings, selection into parenthood, and second birth progressions. MPIDR Working Paper WP 2020-029. Rostock: Max Planck Institute for Demographic Research. https://doi.org/10.4054/MPIDR-WP-2020-029

OECD 2011: Education at a Glance, Editorial: “Fifty Years of Change in Education" [http:// www.oecd.org/education/skills-beyond-school/48642586.pdf, 09.11.2021].

Oppenheimer, Valerie Kincade 1988: A theory of marriage timing. In: American Journal of Sociology 94,3: 563-591. http://dx.doi.org/10.1086/229030

Oppenheimer, Valerie Kincade 1994: Women's rising employment and the future of the family in industrial societies. In: Population and development review 20,2: 293-342. https://doi.org/10.2307/2137521

Oppenheimer, Valerie Kincade 1997: Women's employment and the gain to marriage: The specialization and trading model. In: Annual review of sociology 23: 431-453. https://doi.org/10.1146/annurev.soc.23.1.431

Raymo, James M. et al. 2015: Educational differences in early childbearing: A crossnational comparative study. In: Demographic Research 33,3: 65-92. https://dx.doi.org/10.4054/DemRes.2015.33.3

Rindfuss, Ronald R.; St. John, Craig 1983: Social determinants of age at first birth. In: Journal of Marriage and the Family 45,3: 553-565. https://doi.org/10.2307/351660

Shang, Qingyan; Weinberg, Bruce A. 2013: Opting for families: Recent trends in the fertility of highly educated women. In: Journal of Population Economics 26,1: 5-32. https://doi.org/10.1007/s00148-012-0411-2

Stange, Kevin 2011: A longitudinal analysis of the relationship between fertility timing and schooling. In: Demography 48,3: 931-956. https://doi.org/10.1007/s13524-011-0050-3

Steiber, Nadia; Berghammer, Caroline; Haas, Barbara 2016: Contextualizing the Education Effect on Women's Employment: A Cross-National Comparative Analysis. In: Journal of Marriage and Family 78: 246-261. https://doi.org/10.1111/jomf.12256

Thévenon, Olivier 2011: Family policies in OECD countries: A comparative analysis. In: Population and development review 37,1: 57-87. https://doi.org/10.1111/j.1728-4457.2011.00390.x

Trimarchi, Alessandra; Van Bavel, Jan 2020: Partners' Educational Characteristics and Fertility: Disentangling the Effects of Earning Potential and Unemployment Risk on Second Births. In: European Journal of Population 36: 439-464. https://dx.doi.org/10.1007/s10680-019-09537-w

Vignoli, Daniele; Tocchioni, Valentina; Mattei, Alessandra 2020: The impact of job uncertainty on first-birth postponement. In: Advances in Life Course Research 45,100308. https://doi.org/10.1016/j.alcr.2019.100308 
554 - Natalie Nitsche, Anna Matysiak, Jan Van Bavel, Daniele Vignoli

Dr. Natalie Nitsche $(\triangle)$. Max Planck Institute for Demographic Research. Rostock, Germany. E-mail: nitsche@demogr.mpg.de

URL: https://www.demogr.mpg.de/en/about_us_6113/staff_directory_1899/natalie_ nitsche_3776

Prof. Dr. Anna Matysiak. University of Warsaw. Warsaw, Poland.

E-mail: amatysiak@wne.uw.edu.pl

URL: http://www.annamatysiak.com/

Prof. Dr. Jan Van Bavel. University of Leuven, Centre for Sociological Research. Leuven, Belgium. E-mail: Jan.VanBavel@kuleuven.be

URL: https://www.kuleuven.be/wieiswie/en/person/00002662

Prof. Dr. Daniele Vignoli. University of Florence. Florence, Italy.

E-mail: daniele.vignoli@unifi.it

URL: www.danielevignoli.com 


\section{Comparative Population Studies}

WWW.comparativepopulationstudies.de

ISSN: 1869-8980 (Print) - 1869-8999 (Internet)

\section{Published by}

Prof. Dr. Norbert F. Schneider

Federal Institute for Population Research D-65180 Wiesbaden / Germany

\section{(c) BY-SA}

2021

\section{Managing Editor}

Prof. Dr. Johannes Huinink

Dr. Katrin Schiefer

\section{Editorial Assistant}

Beatriz Feiler-Fuchs

Wiebke Hamann

\section{Layout}

Beatriz Feiler-Fuchs

E-mail:cpos@bib.bund.de

\section{Scientific Advisory Board}

Karsten Hank (Cologne)

Michaela Kreyenfeld (Berlin)

Marc Luy (Vienna)

Natalie Nitsche (Rostock)

Zsolt Spéder (Budapest)

Rainer Wehrhahn (Kiel)

\section{Board of Reviewers}

Bruno Arpino (Barcelona)

Kieron Barclay (Rostock)

Laura Bernardi (Lausanne)

Gabriele Doblhammer (Rostock)

Anette Eva Fasang (Berlin)

Michael Feldhaus (Oldenburg)

Tomas Frejka (Sanibel)

Alexia Fürnkranz-Prskawetz (Vienna)

Birgit Glorius (Chemnitz)

Fanny Janssen (Groningen)

Frank Kalter (Mannheim)

Stefanie Kley (Hamburg)

Bernhard Köppen (Koblenz)

Anne-Kristin Kuhnt (Duisburg)

Hill Kulu (St Andrews)

Nadja Milewski (Wiesbaden)

Roland Rau (Rostock)

Thorsten Schneider (Leipzig)

Tomas Sobotka (Vienna)

Jeroen J. A. Spijker (Barcelona)

Heike Trappe (Rostock)

Helga de Valk (The Hague)

Sergi Vidal (Barcelona)

Michael Wagner (Cologne) 